\title{
Adaptation Strategies to Climate Change among Rice Farmers in Katsina-Ala Local Government Area of Benue State, Nigeria
}

\author{
Naswem, A.A. ${ }^{1}$, Akpehe, G.A. ${ }^{2}$, Awuaga, M.N. ${ }^{1}$ \\ ${ }^{I}$ Department of Agricultural Extension and Communication, University of Agriculture, Makurdi, Benue State, \\ Nigeria. \\ ${ }^{2}$ Department of Sociology, Benue State University, Makurdi, Benue State, Nigeria.
}

\begin{abstract}
Climate change has emerged as an important factor in agricultural production globally. Advanced countries are better placed to address the challenges posed by this phenomenon. Developing countries must also develop the capacity to tackle this problem in order to ensure sustainable agriculture. A foundational requirement is to access the knowledge, attitude and practice of local farmers in order to design a robust response to support their activities. The study was aimed at assessing the farmers' level of awareness of climate change and the strategies they adopt in response to it. The results show a high level of awareness of climate change, and that farmers employ various commonsense strategies to mitigate its effects.
\end{abstract}

Keywords: Climate change, Rice farmers, Adaptation, Mitigation, Awareness.

\section{Introduction}

Climate change poses a very serious threat to sustainable agricultural production and food security in many parts of the world. Itaffects crop yield, prices, production, consumption, and nutrition. Studies have indicated that agriculture in developing countries is currently being affected by climate change (UNDP, 2006). Climate change, defined as any sustained alteration in the average daily weather pattern resulting from natural courses of events or human activity (Easterling et al. 2007, IPCC 2007. Climate change is a global phenomenon that had varied definitions depending authors' conceptions and perceptions. IPCC (2007) defined climatic change as a change in the state of the climate that can be identified (e.g. using statistical tests) by changes in the mean and/or the variability of its properties, and that persists for an extended period, typically decades or longer. According to Olaniyi, Ojekunle and Amujo (2013), climate change refers to an increase in average global temperatures attributable to natural events and human activities leading to increase in greenhouse gases such as Carbon Dioxide (CO2).

However, Olaniyi et al (2013) aligned themselves with the United Nations Framework on Climate Change (UNFCC) which used the term "Climate Change" to refer to human-induced change while the term "Climate Variability" is used for changes due to external forces. The 'external forces' here entails the changes in climate caused by analteration in the global energy balance as a result of fluctuations in the Earth's orbit, ocean circulation, and atmospheric composition. The humanly induced factors comprise all activities such as deforestation, fossil fuel consumption, urbanization, land reclamation, agricultural intensification, freshwater extraction, fisheries over-exploitation and waste production (Handmer et al, 2012).

The literature also dwell on the impacts of climate being felt by both developed and developing countries. In Nigeria, desertification has been identified as a particularly serious problem. Olagunju, (2015). The changing climatic conditions according to Food and Agricultural Organization (FAO) (2016) projections would affect food security as patterns of rainy season would be reduced, and the frequency and intensity of severe weather events such as floods, cyclones and hurricanes would increase; prolonged drought, shortages and changes in the location and incidence of pest and disease outbreaks would be experienced in some locations globally (FAO, 2016).

Climate change adaptation comprises all spontaneous and premeditated action taken to cope with the impacts of, or reduce vulnerability to, a changing climate. Adaptation shouldaddress immediate problems and anticipate future changes in order to mitigate adverse effects. Adaptation strategies can be preemptive or responsive private and public adaptation, and autonomous and planned adaptation. All adaptation strategies aim at promoting resilience and reducing vulnerability (IPCC, 2012)

Rice is one of the most important cereal crops in Nigeria. Its consumption is increasing rapidly in Nigeria because of urbanization, relative ease of preparation, and convenience in storage. With the increased availability of rice, it has become part of the everyday diet of many in Nigeria. There are many varieties of rice grown in Nigeria. Some of these are considered 'traditional' varieties, others have been introduced within the last twenty years. Rice is grown in paddies or on upland fields, depending on the requirements of the particular variety. New varieties are produced and disseminated by research institutes, or are imported from Asia. Nigeria 
is one of the biggest producers of all types of rice in Africa (Baksh, 2003) and Benue State is a major producer in Nigeria (Cadoni and Angelucci, 2013).

Under the Agricultural Transformation Agenda (ATA) rice is one of the focal crops that the Federal Government intends to use to lift rural farmers from poverty. This is because of its high marketability both locally and internationally. It is therefore necessary to position farmers to take advantage of government support of the rice sector. One major problem that would be encountered in this regard is the rapid climate change taking place globally. The scheme would fail if farmers are not equipped to adapt to the vagaries of the weather. An audit of farmers' knowledge, attitudes and practices would lay bare specific gaps that need to be filled in rice farmers' adaptation capacities. Since agricultural policy is evolutionary, this kind of data would provide the impetus for fine-tuning and adapting the policy to accommodate the changes, sometimes extreme, in climatic elements that impinge on the rice enterprise.

From the foregoing, the following research questions are important to this study;

i) To what extent are rice farmers aware of climate change?

ii) What are rice farmers' sources of information on climate change area?

iii) What adaptation strategies do rice farmers adopt to mitigate the impact of climate change?

The broad objective of the study was to examine adaptation strategies to climate change among rice farmers in Katsina-Ala Local Government area of Benue State, Nigeria. The specific objectives of this study using the earlier stated research questions are to:

i) Determine rice farmers' level of awareness of climate change;

ii) Ascertain rice farmers' sources of information on climate change.

iii) Identify adaptation strategies to the impact of climate change on rice production;

\section{Methodology}

This study covers KatsinaAla Local Government Area of Benue State, Katsina-Ala is essentially inhabited by the Tiv. There exist other ethnic groups like the Hausas and Etulos The Local Government is located in the north-eastern part of Benue State. The area lies between the transition zone of the Guinea and Savannah vegetation with the Northern portion consisting of undulating hills and shrubs. The Local Government Area experiences two main seasons, the dry season starts in late October and usually ends by March; and the rainy season which starts in April and lasts till early October. Prominent geographical feature in the area include River Katsina-Ala which runs from south-west along the border to North-west, with its tributaries of Loko and Logo tearing through the Local Government Area midway into the south and northern ends respectively, Yooyo, the Lake Akata andHarga and Dikkpo hills.

The people of the area are largely farmers producing mainly yam, cassava, guinea corn, maize, millet, rice, soybeans, beans, ground nut, sugarcane, fruits, Bambara nut, pepper, and vegetable which are the principal food and cash crop interspersed with fishing and commercial activities mostly carried out by theEtulos and Hausas settlers.

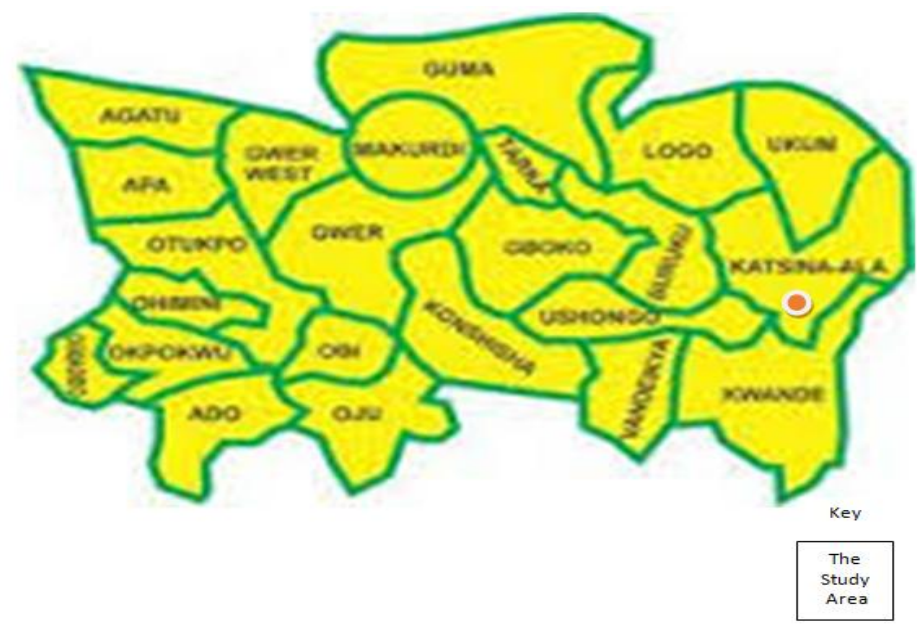

The population of this study consists of all male and female rice farmers in Katsina-Ala Local Government of Benue State.Multi-stage, purposive and simple random techniques were adopted in sampling the respondents. In the first stage, 6 council wards out of the 12 council wards in the Local Government were purposivelychosen to include the major rice producing areas in the study area. These council wards are Utange, Mbayongo, Ikurav-Tiev I, Ikurav-Tiev II, Tiir, and Iwar. In thesecond stage of sampling, three villages were randomly chosen from the lists of rice producing villages in each council ward making a total number of 18 
villages in the sample. Thus, Ahuhaallev, Gawa and Gbise were selected from Mbayongo council ward, Ngibo, Lunjo and Awule-gbev were selected from Ikurav-TievI council ward, Atov-huha, Gbayan and Zaan wereselected from Ikurav-Tiev II council ward, TseAdanyi, TseWombo and TseUli were selected from Tiir council ward, TseAmenger, TseAnyiatse and TseApera were selected from Iwar, TseHaa, TseAlakali and TseTion-kwase were selected from Utange.The sampling frame for the study was obtainedfrom Benue River Basin Development Authority from which a sample of 123 male and female rice farmers was selected.The data was analyzed using descriptive statistics

\section{Results and Discussion}

\section{Rice farmers' level of Awareness of Climate Change}

Table 1 revealed that 21.14 percent of respondents were highly aware of climate change and 39.02 percent were aware. Thus there was a high level of awareness of climate change in the study area. Farmers' awareness of changes in climate attributes is important for adaptation decision making(Madobi, 2012).Table 2 also revealed thatthe main indicators of climate change include 'too much sun,' 'too much rainfall'and variation in rainfall duration. Others include alteration in cropping calendar due to weather, prolonged dry and rainy seasons, thunderstorm and heavy rains and variation in daylight and day night length.The high level of awareness of climate change is based on a limited definition of climate change in terms of weather variability. In most developing countries illiteracy is often a barrier to a robust appreciation of the root causes of climate change and its global dimension (Acquah, 2011; Muzari and Mutumbara, 2014). A sound understanding of the dynamics of climate change is essential if effective attitudinal and behavior change programmes are to be designed and executed. Properly gauging farmers'level of awareness is a fundamental step toward such programmes.

Table 1. Awareness of Climate Change

\begin{tabular}{|l|l|l|}
\hline Variable & Frequency & Percentage \\
\hline Awareness & & \\
\hline Highly Aware & 26 & 21.14 \\
\hline Aware & 48 & 39.02 \\
\hline Moderately Aware & 21 & 17.08 \\
\hline Not Aware & 28 & 22.76 \\
\hline & & \\
\hline Climate Change Indicators & & \\
\hline Variation in rainfall duration, pattern and intensity & 27 & 21.95 \\
\hline Too much sun and too much rain & 30 & 24.39 \\
\hline Alteration to cropping calendar due to weather & 17 & 13.83 \\
\hline Variation in flood pattern, duration and intensity & 07 & 5.69 \\
\hline Prolonged dry and rainy seasons & 14 & 11.38 \\
\hline Thunderstorms and heavy rains & 15 & 12.38 \\
\hline Variation in harmattan pattern and intensity & 07 & 5.69 \\
\hline Variation in day light and night length & 06 & 4.88 \\
\hline
\end{tabular}

Source: field survey, 2014

\section{Sources of information on climate change of the respondents}

Table 3 shows that personal observation/experience, Radio/television,and fellow farmers were the major sources of information.Chen et al., (2010) supported the significance of climate change information sharing in facilitating adaptation in China. The study also confirmed the accuracy of farmer's perceptions. These findings also concur with Isife and Ofuoku (2008), who documented that radio, has the highest audience and has the strength of reaching a large population of farmers and other rural dwellers faster than other means of communication. In Zimbabwe, however, Madobi (2012) reported that radio and television were not important sources of information on climate change because of the low credibility these sources commanded in that country.

Table 2: Sources of Information on Climate Change

\begin{tabular}{|l|l|l|}
\hline Variable & Frequency & Percentage \\
\hline Personal observation/Experience & 36 & 29.27 \\
\hline Radio/Television & 36 & 29.27 \\
\hline Extension Agent & 8 & 6.50 \\
\hline Fellow Farmers & 25 & 20.33 \\
\hline Newspapers & 9 & 7.32 \\
\hline Internet & 7 & 5.69 \\
\hline None & 2 & 1.63 \\
\hline
\end{tabular}

Source: field survey, 2014 


\section{Adaptation Strategies to climate in Rice Production}

Table 3presents the strategies that rice farmers adopted in response to climate change. The major strategies employed included the use of improved varieties. Almost 15 percent(14.63) of the respondents adopted this strategy. Another major strategy adopted by farmers was growing drought resistant crops varieties(13.82\% of the respondents). Other strategies identified by rice farmers includeout-migration from climate risk zones prayers for God's intervention, multiple cropping, adoption of recommended improved rice production strategies, recycling of waste product and improvement on farmers' management skills.these strategies have also been adopted by farmers in other countries to address production and other challenges occasioned by climate change (Mburu et al, 2015; African Technology Policy Studies Network, ATPS 2013; Orindi and Eriksen 2005). Some effects of climate change cannot be handled by the farmers. Government would be requiredto take action in certain directions like enacting and enforcing the use of clean energy, and the drive towards reforestation (Farauta et al, 2011)

Table 3 Rice Farmers' Adaptation Strategies to Climate Change

\begin{tabular}{|l|l|l|}
\hline Variables & Frequency & Percentage \\
\hline Use of improved varieties & 18 & 14.63 \\
\hline Growing drought resistant crop varieties & 4 & 3.25 \\
\hline Growing flood resistant varieties & 6 & 4.88 \\
\hline Use of pest/disease resistant varieties & 5 & 4.07 \\
\hline Crop diversification & 2 & 1.63 \\
\hline Prayers for God's intervention & 3 & 2.44 \\
\hline Multiple cropping & 2 & 1.63 \\
\hline Construction of drainage system & 2 & 1.63 \\
\hline Use of suitable irrigation system & 4 & 3.25 \\
\hline Out-migration from climate risk zones & 15 & 12.20 \\
\hline Adoption of recommended improved rice production strategies & 2 & 1.63 \\
\hline Adjusting the planting calendar & 11 & 8.94 \\
\hline Moderate use of agro-chemicals and fertilizers & 17 & 13.82 \\
\hline Recycling of waste product & 5 & 4.07 \\
\hline Improvement on farmer's management skills & 2 & 1.63 \\
\hline Increase irrigation & 4 & 3.25 \\
\hline Change use of chemicals, fertilizers, and pesticides & 21 & 17.07 \\
\hline
\end{tabular}

Source: field survey, 2014

\section{Conclusion}

Rice farmers in the study area demonstrated a high level of awareness of the climate change phenomenon and have responded to it to the best of their abilities. The major source of information on climate change in the study area was the use of observation/experience and radio/television. Their knowledge and perception of climate change phenomenon substantially directed at thevariation in rainfall duration, pattern and intensity, too much sun and too much rain, alteration in cropping calendar due to weather and thunderstorm and heavy rains. The adaptation strategies mostly used by the respondents were theuse of improved varieties, change theuse of chemicals, fertilizers, and pesticide, adjusting the planting calendar, out-migrationfrom climate risk zones and moderate use of agro-chemicals and fertilizers. Extension services appeared to be contributing little to the awareness of the farmers on climate change hence the general awareness of variation in local weather patterns. The low impact of the agricultural extension services highlights the need for the reinvigoration of, and mainstreaming of climate smart agriculture extension service

Based on the findings of this study, the following recommendations were made:

a. The extension service should be strengthened to provide adequate information on climate change to farmersin the study area.

b. Adequate and regular information on current issues related to the effect of climate change on agriculture be provided to the respondents through mass media campaign especially radio.

c. Agricultural policies must be overhauled to make them Climate smart. This will provide the template for all stakeholders to carry out robust mitigation strategies to counter the negative effects of climate change.

d. Early maturing, drought resistant and flood resistant varieties of rice should be made available to farmers to enable them to cope with the vagaries of the climate.

\section{References}

[1] AcquahHDG, (2011) Public Awareness and Quality ofKnowledge Regarding Climate Change in Ghana: A Logistic Regression Approach. Journal of Sustainable Development in Africa. Vol. 13, (3) pp. 146-157,

[2] African Technology Policy Studies Network, ATPS 2013: Farmers' Response and Adaptation Strategies to Climate Change in Mafeteng District, Lesotho [Tsepo Stephen Tiisetso Sekaleli, Karabo Sebusi], ATPS WORKING PAPER No. 74

[3] Baksh D, 2003. The right way to process rice, Journal African Farm, 26 
[4] Cadoni P and Angelucci F 2013. Analysis of incentives and disincentives for Rice in Nigeria. Technical notes series, MAFAP, FAO, Rome

[5] Chen L, Zuo T and Rasaily RG (2010). Farmers' adaptation to climate risk in the context of China. Aresearch on Jianghan Plain of Yangste River Basin. Agriculture and Agricultural Science Procedia, Vol $1: 116-125$.

[6] Easterling WE, Aggarwal PK, BatimaP, BranderKM, ErdaL, HowdenSM, Kirilenko A, MortonJ, SoussanaJF, Schmidhuber J and Tubiello FN(2007)Food, fibre and forest products. Climate Change 2007: Impacts, Adaptation and Vulnerability. Contribution of Working Group II to the Fourth Assessment Report of the Intergovernmental Panel on Climate Change, M.L. Parry, O.F. Canziani, J.P. Palutikof, P.J. van der Linden and C.E. Hanson, Eds., Cambridge University Press, Cambridge, UK, $273-313$.

[7] Farauta BK, ChukwudumebiLE, and Idrisa, YL (2011) Climate Change and Adaptation Measures in Northern Nigeria: Empirical Situation and Policy Implications African Technology Policy Studies Network Working Paper Series No. 62.

[8] FAO (2016) Managing Climate Risk Using Climate-Smart Agriculture, Rome, Food and Agricultural Organization of the United Nations.

[9] Handmer J, HondaY, KundzewiczZW, ArnellN, BenitoG, HatfieldJ, MohamedIF, Peduzzi P, WuS, SherstyukovB, TakahashiK, and YanZ, 2012: Changes in impacts of climate extremes: human systems and ecosystems. In: Managing theRisks of Extreme Events and Disasters to Advance Climate Change Adaptation [Field CB, BarrosV, StockerTF, QinD,Dokken DJ, EbiKL, MastrandreaMD, MachKJ, PlattnerG-K, AllenSK, TignorM, and Midgley PM (eds.)]. A SpecialReport of Working Groups I and II of the Intergovernmental Panel on Climate Change (IPCC). Cambridge University Press, Cambridge, UK, and New York, NY, USA, pp. 231-290.

[10] Intergovernmental Panel on Climate Change (IPCC) (2007), Fourth Assessment Report, Cambridge University Press, Cambridge, UK.

[11] IPCC(2012): Managing the Risks of Extreme Events and Disasters to Advance Climate Change Adaptation. A Special Report of Working Groups I and II of the Intergovernmental Panel on Climate Change [Field, C.B., V. Barros, T.F. Stocker, D. Qin,D.J. Dokken, K.L. Ebi, M.D. Mastrandrea, K.J. Mach, G.-K. Plattner, S.K. Allen, M. Tignor, and P.M. Midgley (eds.)]. Cambridge University Press, Cambridge, UK, and New York, NY, USA, 582 pp.

[12] Isife, BIand Ofuoku, AU (2008), Communication in Agricultural Extension and Rural Development: Methods and Concepts. Owerri: Springfield Publication.

[13] Madobi R(2014) The Role of Public Awareness in Climate Change Mitigation and Adaptation in Zimbabwe. International Journal of Science and Research Volume 3 Issue 11, p.1270-1275. Retrieved from http://www.ijsr.net/archive/v3i11/T0NUMTQ4MzE\%3D.pdf on 20/06/2016

[14] Mburu BK, Kung'u JB and Muriuki JN (2015) 'Climate change adaptation strategies by small-scale farmers I Yatta District, Kenya, African Journal of Environmental Science and Technbology, 9 (9) 712-722

[15] Muzari W and Mutambara J (2014) Climate Change and Gender Impacts on Development among Rural Communities, International Journal of Science and Research 3 (9) 1752-1756. Retrieved from: http://www.ijsr.net/archive/v3i9/U0VQMTQzMTU\%3D.pdfon $30 / 06 / 2016$

[16] Olagunju TE (2015) Drought, Desertification and the Nigerian Environment: A Review, Journal of Ecology and the Natural Environment. Vol. 7 (7) 196-209.

[17] Orindi VA and Eriksen S 2005. Mainstreaming adaptation to climate change in the development process in Uganda. Ecopolicy Series no. 15, African Centre for Technology Studies, Nairobi, Kenya

[18] United Nations Development Programme (2006) Human Development Report 2006: Beyond Scarcity:Power and the Global Water Crisis, New York: MacMillan 